\title{
A Fact-Oriented Approach In Macro-Case Analysis: A Section 385 Illustration
}

Wei-Chih Chiang, University of Houston - Victoria, USA Ted D. Englebrecht, Louisiana Tech University, USA

\begin{abstract}
Prior research has not adequately addressed the coding issue in macro-case analysis research. This study provides a fact-oriented approach (in contrast to the traditional opinion-oriented approach) to deal with this issue. We argue that while a traditional opinion-oriented approach can reveal the influential factors considered by judges in the precedents, a fact-oriented approach provides a decision model with predictability which does not exist in an opinion-oriented approach. The differences between these two approaches are demonstrated by applying them to the Code Section 385 dilemma (i.e., the debt-equity classification). Results show that decision models developed by these two approaches are very different but with similar classification accuracy. Consequently, management and practitioners can use a fact-oriented approach as a supplemental method to the traditional opinion-oriented approach to predict the judicial outcome.
\end{abstract}

Keywords: Macro-Case Analysis; Court Case Study; Section 385; Debt-Equity Classification

\section{INTRODUCTION}

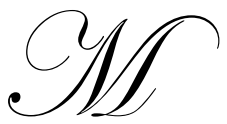

acro-case analysis (Misiewicz 1977) engages the aggregate analysis on factors considered by the court on a tax issue over a period of time. The information generated by macro-case analysis can "facilitate tax research for compliance and especially for planning" (Misiewicz 1977, p. 938). Although Horvitz and Finley (1979) argue that macro-case analysis is not an effective substitute for traditional legal research, numerous studies have applied macro-case analysis in diverse tax areas (e.g., Kramer 1982; Porcano 1982; Burns \& Groomer 1983; Robison 1983; Pollard \& Copeland 1987; Robertson et al. 1990; Englebrecht \& Bundy 2004; Barniv et al. 2005; Webb et al. 2008; Englebrecht et al. 2008).

One key advantage of macro-case analysis is the ability to choose objectively determinable factors and, hence, minimize the subjectivity inherent in traditional legal research (Misiewicz 1979). However, even though the determinable factors could be objectively chosen in macro-case analysis, how to evaluate these factors ("the coding issue") is a critical concern that prior research has not addressed. For example, in resolving the classification of debt versus equity ("the debt-equity issue"), courts may consider the factor "Identity of Interest." In Flint Industries [TC Memo 2001-176], the Tax Court weighs "Identity of Interest" factor in favor of equity where sole ownership is present, but the Tax Court in Westin [TC Memo 1987-238] treats this factor as neutral under the same situation. Facing these two cases, how does a researcher code the "Identity of Interest" factor? Would the researcher code this factor in these two cases both toward equity, both neutral, or one toward equity and one neutral?

This study provides "a fact-oriented approach" to deal with the coding issue in macro-case analysis research. Essentially, prior research relies on judicial opinions ("an opinion-oriented approach") to encode determinable factors. In contrast, a fact-oriented approach codes factors in light of objective facts wherever possible. As a result, a fact-oriented approach provides a decision model with predictability that does not exist in an opinionoriented approach. This paper applies both the fact-oriented and opinion-oriented approaches to cases related to the debt-equity issue to demonstrate the potential differences. We conclude that management can use a fact-oriented approach as a supplemental method to the traditional opinion-oriented approach to predict the judicial outcome. 
The remainder of this article is structured as follows: section two argues the need for a fact-oriented approach and addresses the research question; section three covers research methodology; section four provides the empirical results; and the last section presents the conclusion, limitations, and future research opportunities.

\section{A SUPPLEMENTAL APPROACH AND RESEARCH QUESTION}

\section{The Debt-Equity Issue}

To implement its financial policies, management could choose internal (i.e., earnings) or external (e.g., debt and equity financing) sources. Since the tax law treats debt and equity financing differently, hybrid instruments such as convertible bonds, which are viewed as debt for tax purposes but as equity for financial accounting purposes, have become very popular. However, Notice 94-47 [1994-1 CB 357] states the intent of the Internal Revenue Service (hereafter IRS or Service) to scrutinize these types of financial instruments. The Internal Revenue Code (IRC) Section 385 gives the IRS authority to impose guidance in resolving the debt-equity issue and indicates that the following five factors should be included in the potential regulations: (1) written unconditional promise to pay on demand, or on a specified date, a sum certain in money and to pay a fixed interest rate; (2) subordination or superiority to other creditors; (3) debt to equity ratio; (4) convertibility into stock; and, (5) the relationship between stockholders and the providers of the interest at issue. Although the IRS announced final regulations on January 1, 1981 [T.D. 7747, 1981-1 CB 141] and made several amendments [T.D. 7774, 1981-1 CB 168, T.D. 7801, 1982-1 CB 60, and T.D. 7822, 1982-2 CB 84], the IRS withdrew these regulations before they became effective [T.D. 7920, 1983-2 CB 69]. As a result, lack of administrative guidance leads to extensive litigation between the Service and taxpayers. Accordingly, some judicial guidelines have been promulgated to assist courts in resolving the debt-equity dilemma (e.g., a 13 factors test in Estate of Mixon [464 F.2d 394 ( $5^{\text {th }}$ Cir. 1972)] and a 16 factors test in Fin Hay Realty Co. [398 F.2d 694 ( $3^{\text {rd }}$ Cir. 1968)]). Subsequently, the IRS incorporated several judicial guidelines in Field Service Advice 200205031, which lists 12 factors that courts commonly rely on: (1) Name: the name and presence of a written agreement evidencing the indebtedness; (2) Maturity Date: the presence of a fixed maturity date; (3) Source of Payment: the source of payments; (4) Rights to Enforce: the right to enforce payment of principal and interest; (5) Management: increased participation in management as the result of the advance; (6) Subordination: inferior or superior to other creditors; (7) Capitalization: thinness of the capital structure; (8) Identity of Interest: identity of interest between creditor and stockholder; (9) Payment of Interest: source of interest payments from earnings; (10) Outsider Loan: the ability of the corporation to obtain loans from outside creditors; (11) Use of Advance: the extent to which the advance was used to acquire capital assets; and, (12) Failure of Repaying Advance: the failure of the debtor to repay.

Several studies (Bond 1977; Whittington \& Whittenburg 1980; Robertson et al. 1990; Englebrecht et al. 2008) apply macro-case analysis to the debt-equity issue. Generally, most of these studies employ discriminant analysis to find the "best" model as well as influential factors, and they adopt the holdout sample technique to test the model's stability over the sample periods. Although the influential factors found in these studies are not identical, the model's stability is generally confirmed.

\section{The Coding Issues and Outcome Predictability Limitation}

Despite the popularity of macro-case analysis, using multiple discriminant analysis to develop relatively simple decision models of complex tax relationships has been questioned in regards to the robustness of their findings (Pollard \& Copeland 1985). Applying an error seeding method, Pollard and Copeland (1985) evaluate the robustness of their tax decision models where random errors or systematic errors are embedded. Furthermore, Pollard and Copeland (1987) test several sensitivity analyses of their tax decision models by comparing the classification accuracy of linear and quadratic functions and by comparing the classification accuracy of discriminant and PROBIT models. Moreover, Copeland et al. (1981) find that, in tax modeling, observation error which refers to measurement inaccuracies made by an observer is significantly related to the observer's bias.

Other than the potential error issue, how to code the independent variables is another critical concern that has not been adequately addressed in prior macro-case analysis research. Typically, prior studies briefly mention the coding method, but only to the extent of when to code a factor as "yes," "missing," or "no" (e.g., Burns \& Groomer 
1983; Pollard \& Copeland 1985; Robertson et al. 1990; Englebrecht \& Bundy 2004). Even though the coding issue relating to missing data is normally discussed (e.g., Robison 1983), the coding problem is not extensively examined in prior research.

We define a traditional opinion-oriented approach as a method employed by a macro-case analysis study that follows a court's opinion in coding or does not address the coding issue at all. To illustrate the drawbacks of an opinion-oriented approach, we later present examples related to the debt-equity issue.

Generally, the coding issue could appear in two situations. First, regarding a particular variable, the court's opinion does not match the objective fact. A fact is an event related to a factor that the court uses to distinguish debt from equity. An opinion is the court's judgment in light of the facts in favor of debt or equity. Essentially, most of the questions used in collecting the relevant data from judicial decisions are presented in the form of requesting facts rather than courts' opinions (see, for example, Bond 1977, p. 39, Exhibit 2-1; Whittington \& Whittenburg 1980, p. 413, Table 1; Robertson et al. 1990, p. 710, Table 1). However, the court's opinion does not always follow these objective facts. For example, the following is one question commonly asked in collecting data, "Is the name of the instrument indicative of debt" (question 15 in Bond (1977) and question 13 in Robertson et al. (1990))? Specifically, the answer of "Yes" means the objective fact is in favor of debt. In Hubert Enterprises, Inc. [125 TC 6], the fact that a note is issued for the transfer in question indicates the factor of "Name" should be weighed toward a bona fide debt. Nevertheless, based on other factors that showed no fixed maturity date, no interest provision, no collateral, and no meaningful repayments, the court weighed the "Name" factor toward a finding of equity.

Second, different courts may conclude different opinions regarding the same objective fact. For example, given the fact that the transferee could obtain loans from outside creditors under different terms, the Tax Court in Laidlaw Transportation, Inc. [TCM 1998-232] weighed the factor of "Outsider Loan" toward equity, but in Nachman [TCM 1996-288], the Tax Court weighed this factor neutral in light of the same fact. This inconsistency between objective facts and courts' opinions occurs in other criteria such as "Identity of Interest," "Management," and "Failure of Repaying Advance.",

Apparently, these two coding issues lead to the inconsistent definitions of the independent variables under the traditional opinion-oriented approach. That is, although the label of a factor is identical, the meanings of this factor could be very different in two cases. Due to this definition inconsistency, the decision models established under the traditional opinion-oriented approach could become meaningless.

Bond (1977, p. 132) acknowledges the first coding scheme issue and decides to make the coding in accordance with "whether the judge felt the factor reflected debt or equity." Notwithstanding that Bond's coding rule would not raise any confusion in coding, the definitional inconsistency issue is not solved under Bond's rule. Furthermore, Bond's rule will move the decision model toward solely evaluating subjective judicial opinions. Establishing a tax decision model based on courts' subjective opinions could provide insights into the influential factors considered by the judges in the precedents but not the function of predicting a court's decision.

One application of an established tax decision model is to assist in tax planning or litigation (Bond 1977; Whittington \& Whittenburg 1980; Porcano 1982; Burns \& Groomer 1983; Robison 1983; Robertson et al. 1990; Englebrecht \& Bundy 2004). Nevertheless, where an opinion-oriented decision model is exclusively based on courts' subjective opinions, the outcome prediction becomes unfeasible. Specifically, judicial opinions on factors in a particular case are revealed only when the decision is made. That is, a petitioner cannot know the court's opinions on the factors before the case is decided. Therefore, the petitioner is unable to "predict" the outcome of the case while using an opinion-oriented decision model. Hence, even though an opinion-oriented decision model could perfectly classify all of the cases from which the model is established, the model does not provide much useful ex ante information for the case outcome prediction. Actually, Bond (1977) notices this limitation and states:

Two decision rules were developed to classify the cases used in this sample. These rules may or may not be useful in predicting the outcome of a case not in the sample. In fact, the first of these rules involves knowing the judge's opinion before the case can be classified. ... Therefore, caution must be exercised in using this model to predict the outcome of a new, untried case. The model cannot be used to predict outcomes of untried cases; rather, it highlights ... factors that have been emphasized in previous Tax Court cases (pp. 132-133). 


\section{The Fact-Oriented Approach}

A supplemental approach to avoiding the coding issues and improving the predictability is to establish a decision model in light of objective facts. A fact-oriented approach codes factors in view of objective facts wherever possible. In other words, the main difference between the two approaches is that the coding in a fact-oriented decision model is based on the objective facts presented in the opinion section of the cases rather than the courts' subjective opinions. For example, the "Name" factor in the aforementioned case of Hubert Enterprises, Inc. is coded in favor of equity in an opinion-oriented decision model, but it will be coded toward debt in a fact-oriented decision model.

The facts incorporated in a fact-oriented decision model are limited to those presented in the opinion section of the judicial decision. All facts germane to the decision are assumed to be fully discussed in the opinion section (Robison 1983). Therefore, facts mentioned in the section of findings of fact but not discussed in the opinion section are not considered in a fact-oriented decision model. ${ }^{\text {ii }}$ By doing so, a fact-oriented decision model could avoid factors the court did not consider in reaching the decision (Bond 1977, p. 132). ${ }^{\text {iii }}$

Meanwhile, independent variables without the coding issue could follow the definitions used in prior research or judicial guidelines. However, a decision model builder has to define the independent variables where the coding issue is present. For example, for the factor of "Outsider Loan," a researcher has to decide whether "under different terms" should be included in the definition to consolidate the controversial judicial opinions between Laidlaw Transportation, Inc. [TCM 1998-232] and Nachman [TCM 1996-288].

The main advantage provided by a fact-oriented decision model is the improvement in feasible predictability. A fact in a case exists and does not change before and after the litigation. Therefore, by referring to an established fact-oriented decision model, a taxpayer or petitioner could possibly predict the outcome of the court decision in light of the objective facts in the current case. See Table 1 for the summary of comparisons between the opinion-oriented and the fact-oriented approaches.

Table 1: Comparisons between Opinion-Oriented and Fact-Oriented Approaches

\begin{tabular}{lll}
\hline Labels of independent variables & Opinion-Oriented Approach & Fact-Oriented Approach \\
\hline Definitions of independent variables & Definition could be different among cases. & $\begin{array}{l}\text { Definition is established by researchers } \\
\text { and is consistent among cases. }\end{array}$ \\
\hline Independency of variables & $\begin{array}{l}\text { Court may depend on other factors to decide } \\
\text { a particular factor. }\end{array}$ & Independent among factors. \\
\hline Coding rule & Based on court's opinions. & Based on facts in the case. \\
\hline Influential factors & Identified according to court's opinions. & Identified according to facts in the case. \\
\hline Predictability & $\begin{array}{l}\text { None. Court's opinions on factors are } \\
\text { revealed only after the case is decided. }\end{array}$ & $\begin{array}{l}\text { Probably. Facts needed for prediction are } \\
\text { known to the practitioners and their } \\
\text { clients before the decision is made. }\end{array}$ \\
\hline
\end{tabular}

To compare the differences between a fact-oriented model and an opinion-oriented model, the research question is set as follows.

RQ: Does a fact-oriented decision model provide different information relative to an opinion-oriented decision model?

Basically, three issues are investigated to answer this research question. First, influential factors considered by courts from both approaches are compared. Second, model stability is examined in both approaches. Third, judicial forum effect is assessed. The factors used among judicial forums may be different (Kramer 1982). Identifying whether the influential factors used by different judicial forums vary could provide taxpayers beneficial information for litigation purposes. Meanwhile, the Tax Court, the Federal District Courts, and the Court of Federal Claims have original jurisdiction to hear and decide tax cases arising under the IRC. However, due to a lack of court 
cases decided by the Court of Federal Claims, our investigation is limited to the forum effect between the Tax Court and the Federal District Courts.

\section{RESEARCH METHOD}

In this study, we apply two statistical techniques - discriminant analysis and logistic regression. First, the discriminant analysis is used to determine which factors are considered consistently in court decisions. The backward selection procedure is followed to identify the "best" model. Also, splitting data to cross-validate a selected model requires the number of observations to be at least six to ten times the number of the independent variables in the pool (Kutner et al. 2005). However, when the sample size is relatively small, a compromise procedure - the resubstituion method - could be employed instead of the data splitting method (Hair et al. 2005; Johnson 1998). That is, the discriminant function is developed on the entire sample and then applied to classify the same observations. Moreover, the cross-validation method (or the "jackknifing" method) could be used to estimate the probabilities of misclassification (Johnson 1998). Meanwhile, the model's stability is appraised by using a holdout sample method. Specifically, the sample is split into pre-1995 and post-1994 groups so the subsamples cover the equivalent time length and observations. Further, the pre-1995 group is used as the training data and the post-1994 group is the holdout sample. Because relative larger independent variables are included in this study, a holdout sample method is applied after the "best" model is identified. In addition, a dummy variable - "Time" - is employed to test the model stability before and after 1994. Likewise, the holdout sample method and a dummy variable - "Court" - are applied to examine whether factors considered by the Tax Court and the Federal District Courts differ.

Second, the aforementioned procedures are used similarly under the logistic regression analysis. The logistic regression is appropriate when the dependent variable is dichotomous (Kutner et al. 2005). An additional benefit provided by logistic regression analysis is that a counter part to the Chow test (Greene 2003) can be used to examine the model stability and judicial forum effect.

\section{Sample Selection}

Tax Court and Federal District Court cases decided during the years 1982-2008 that deal with the debtequity issue as listed in the Lexis Nexis Academic database are identified. Since judges may change over time, recent judicial decisions can provide updated insights into the court's perspective of resolving the debt-equity issue. Meanwhile, cases in which a traditional factor analysis is not employed, or when using a traditional factor analysis is controversial, are excluded. ${ }^{\text {iv }}$ Furthermore, because legal issues rather than factual issues are focused on in appeal decisions, five cases appealed from the Bankruptcy Courts to the District Courts are excluded. Based on these criteria, the final sample includes 86 Tax Court observations and 12 District Court cases. ${ }^{\mathrm{v}}$

\section{Variables}

The dependent variable is the court's decision on whether the contribution at issue is debt or equity. A court's decision in favor of debt or equity is clear-cut and could be easily identified.

Since Code Section 385(b) provides only a few factors and no final regulations are operative in resolving the debt-equity issue, the independent variables used in this study are obtained from IRS rulings, judicial guidelines, and prior literature. First, 12 factors listed in Field Service Advice 200205031 are included in the models. Second, two variables, "Collateral" and "Sinking Fund" from the Lantz decision $\left[424\right.$ F.2d 1330 ( $9^{\text {th }}$ Cir. 1970)], are integrated in Bond (1977) and Robertson et al. (1990) and are used in our study. Third, "Rights Enforced" and "Formal Documentation," which are used in prior research (Bond 1977; Robertson et al. 1990), also are included in our models. Fourth, in our sample, many decisions rule in favor of equity when note instruments are not present. ${ }^{\mathrm{vi}}$ Bond (1977), Whittington \& Whittenburg (1980), and Robertson et al. (1990) do not have a factor related to this fact in their models. Adding the factor of "No Issuance of Note Instruments" in the model may provide different insight. Finally, an independent variable of "Instrument Issued" is included in our models. Several cases evaluate whether the instrument is issued as a whole rather than merely the name of the instrument. ${ }^{\text {vii }}$ Although both variables 
measure similar characteristics, the definition of "Instrument Issued" is somewhat broader than that of "Name." Overall, 18 independent variables are used in this study.

\section{Coding}

For the dependent variable, " 1 " is assigned if the court's decision is entered for debt, and " 0 " is used if the decision is in favor of equity. For independent variables, "1," "-1," and "0" are coded for factors in favor of debt, equity, and neutral (or missing data), respectively. ${ }^{\text {viii }}$ Although both the fact-oriented and opinion-oriented models include the same independent variables, the coding schemes for these factors in the two models are somewhat different. Basically, the coding scheme in the opinion-oriented decision model follows the judicial opinion. On the other hand, the coding scheme in the fact-oriented model is based on the facts which are defined by researchers. ${ }^{\text {ix }}$ See Appendix for detailed variable definitions and coding schemes.

Coder bias is mitigated through the following process. First, each case is read, analyzed, and coded independently by two coders. Next, the results of coding are compared. If any inconsistency is found, the authors reconcile the difference after rereading the case.

\section{EMPIRICAL RESULTS}

\section{Data Description}

The numbers of observations and decisions from the Tax Court and the Federal District Courts are summarized in Table 2. The numbers of decisions in favor of debt are $11(12.79 \%)$ in the Tax Court and three (25\%) in the District Courts. The debt decision ratio (debt/total observations) in the District Courts is almost twice as large as that in the Tax Court. However, Chi-Squares test of homogeneity indicates that the difference is not significant at the 0.05 level $\left(\chi^{2}=1.2819, \mathrm{p}=0.2575\right)$. This result implies that management need not to choose between the Tax Court and the District Courts regarding the debt decision preference.

\section{Influential Factors}

The variables included in the fact-oriented and the opinion-oriented decision models are compared in Table 3. Panel A in Table 3, using discriminant analysis, shows that the opinion-oriented decision model includes five factors (Source of Payment, No Issuance of Note Instruments, Capitalization, Formal Documentation, and Payment of Interest). The fact-oriented model also consists of five factors (Source of Payment, Capitalization, Payment of Interest, Rights to Enforce, and Management). Nevertheless, the influential factors are not identical under the factoriented and the opinion-oriented approaches. Table 3 Panel B indicates that when logistic regression analysis is employed, the opinion-oriented decision model contains three factors (Source of Payment, Capitalization, and No Issuance of Note Instruments), but the fact-oriented decision model includes only two factors (Source of Payment and Rights to Enforce). It seems that the number of explanatory factors included in fact-oriented models is less than that in opinion-oriented models.

Regarding classification accuracy, the opinion-oriented model is superior to the fact-oriented model when the resubstitution method is employed in logistic regression analysis. However, when the sample is split into a holdout group (the most recent 10 observations) and a training group (the remaining 76 observations) and the maximum likelihood function is established in light of the training data, both the fact-oriented and opinion-oriented models can correctly classify $100 \%$ of the most recent observations. In discriminant analysis, the findings are mixed as to the model classification accuracy. The opinion-oriented model has better classification accuracy in both the resubstitution method and the cross-validation method. Nevertheless, the opinion-oriented model misclassifies one of the most recent 10 observations, but the fact-oriented can correctly classify all of the 10 observations. 
Table 2: Numbers of Observations and Decisions in Courts

\begin{tabular}{|c|c|c|c|c|c|c|}
\hline \multirow[b]{3}{*}{ Year } & \multicolumn{3}{|c|}{ Tax Court } & \multicolumn{3}{|c|}{ District Courts } \\
\hline & \multicolumn{3}{|c|}{ Decisions entered for } & \multicolumn{3}{|c|}{ Decisions entered for } \\
\hline & Debt & Equity & Subtotal & Debt & Equity & Subtotal \\
\hline 1982 & 0 & 3 & 3 & 0 & 1 & 1 \\
\hline 1983 & 0 & 2 & 2 & 0 & 1 & 1 \\
\hline 1984 & 1 & 2 & 3 & 0 & 0 & 0 \\
\hline 1985 & 1 & 4 & 5 & 0 & 0 & 0 \\
\hline 1986 & 0 & 4 & 4 & 1 & 0 & 1 \\
\hline 1987 & 0 & 4 & 4 & 0 & 0 & 0 \\
\hline 1988 & 0 & 4 & 4 & 0 & 0 & 0 \\
\hline 1989 & 2 & 2 & 4 & 0 & 0 & 0 \\
\hline 1990 & 1 & 2 & 3 & 0 & 2 & 2 \\
\hline 1991 & 0 & 4 & 4 & 1 & 0 & 1 \\
\hline 1992 & 0 & 2 & 2 & 0 & 0 & 0 \\
\hline 1993 & 1 & 1 & 2 & 0 & 0 & 0 \\
\hline 1994 & 0 & 1 & 1 & 0 & 0 & 0 \\
\hline 1995 & 1 & 2 & 3 & 0 & 0 & 0 \\
\hline 1996 & 2 & 5 & 7 & 0 & 0 & 0 \\
\hline 1997 & 0 & 8 & 8 & 0 & 0 & 0 \\
\hline 1998 & 0 & 4 & 4 & 0 & 0 & 0 \\
\hline 1999 & 1 & 0 & 1 & 0 & 0 & 0 \\
\hline 2000 & 0 & 4 & 4 & 0 & 0 & 0 \\
\hline 2001 & 0 & 4 & 4 & 0 & 1 & 1 \\
\hline 2002 & 0 & 3 & 3 & 0 & 0 & 0 \\
\hline 2003 & 1 & 1 & 2 & 0 & 1 & 1 \\
\hline 2004 & 0 & 1 & 1 & 0 & 2 & 2 \\
\hline 2005 & 0 & 3 & 3 & 1 & 0 & 1 \\
\hline 2006 & 0 & 4 & 4 & 0 & 1 & 1 \\
\hline 2007 & 0 & 0 & 0 & 0 & 0 & 0 \\
\hline 2008 & 0 & 1 & 1 & 0 & 0 & 0 \\
\hline Total & 11 & 75 & 86 & 3 & 9 & 12 \\
\hline
\end{tabular}

These results are evidence that fact-oriented decision models and opinion-oriented decision models can consist of different influential factors, suggesting two implications. First, because an opinion-oriented decision model requires knowledge of the court's opinions before coding can occur, the model cannot provide a useful, predictive result for a particular case on hand. In contrast, a fact-oriented decision model can make a prediction more available. Second, an opinion-oriented decision model can provide supplemental insights into the judicial process. Although an opinion-oriented decision model cannot disclose manageable factors, the model could reveal the influential factors considered by judges in the precedents. Taxpayers should pay attentions to these factors as well.

\section{Model Stability}

Table 4 shows the test results for model stability. Basically, both the fact-oriented and the opinion-oriented decision models provide equivalent information. First, a dummy variable of "Time" is added in the "best" model. The value of the time dummy variable is "1" for cases decided before 1995 and "2" for cases decided after 1994. The pre-1995 and post-1994 groups include 41 and 45 observations, respectively. The results indicate that the dummy variable of "Time" is not significant in either fact-oriented or opinion-oriented models under either logistic regression or discriminant analysis. Second, when the holdout method is employed, all models have hit ratios higher than the chance criterion probability of $80.25 \%$ (Hair et al. 2005). Third, a counterpart to the Chow test (Greene, 2003 ) is used in the logistic regression. The log-likelihoods for the models based on the entire sample (pre-1995 and post-1994) are calculated. The results are not significant in either the opinion-oriented decision or the fact-oriented 
models. Overall, both the fact-oriented and the opinion-oriented decision models could provide equivalent results regarding model stability.

Table 3: Independent Variables Included in the "Best" Model

Panel A: Discriminant Analysis

\begin{tabular}{|c|c|c|c|c|c|c|}
\hline \multirow[b]{2}{*}{ Variable } & \multicolumn{3}{|c|}{ Opinion-Oriented Model } & \multicolumn{3}{|c|}{ Fact-Oriented Model } \\
\hline & $\begin{array}{l}\text { Partial } R- \\
\text { Square }\end{array}$ & F-value & $p$-value & $\begin{array}{l}\text { Partial R- } \\
\text { Square }\end{array}$ & $F$-value & p-value \\
\hline Source of Payment & 0.2488 & 26.50 & $<.0001 * * *$ & 0.2268 & 23.47 & $<.0001 * * *$ \\
\hline $\begin{array}{l}\text { No Issuance of Note } \\
\text { Instruments }\end{array}$ & 0.0734 & 6.33 & $0.0138 * *$ & & & \\
\hline Formal Documentation & 0.0619 & 5.28 & $0.0242 * *$ & & & \\
\hline Capitalization & 0.0565 & 4.793 & $0.0315 * *$ & 0.0472 & 3.97 & $0.0498 * *$ \\
\hline Payment of Interest & 0.0650 & 5.56 & $0.0208 * *$ & 0.0798 & 6.94 & $0.0101 * *$ \\
\hline Rights to Enforce & & & & 0.1012 & 9.00 & $0.0036 * * *$ \\
\hline Management & & & & 0.0771 & 6.68 & $0.0116^{* *}$ \\
\hline Classification Accuracy & Missed & Correct & & Missed & Correct & \\
\hline Resubstitution & 3 & 83 & & 4 & 82 & \\
\hline Cross-Validation & 5 & 81 & & 7 & 79 & \\
\hline Predict most recent 10 cases & 1 & 9 & & 0 & 10 & \\
\hline
\end{tabular}

** Significant at $0.05 ; * * *$ Significant at 0.01

Panel B: Logistic Regression

\begin{tabular}{|c|c|c|c|c|c|c|}
\hline \multirow[b]{2}{*}{ Variable } & \multicolumn{3}{|c|}{ Opinion-Oriented Model } & \multicolumn{3}{|c|}{ Fact-Oriented Model } \\
\hline & Estimate & S.D. & $p$-value & Estimate & S.D. & $p$-value \\
\hline Intercept & -0.5923 & 0.5555 & 0.2863 & -1.2702 & 0.4938 & $0.0101 * *$ \\
\hline Source of Payment & 3.1086 & 1.0019 & $0.0019 * * *$ & 2.6408 & 0.7599 & $0.0005 * * *$ \\
\hline Capitalization & 1.7916 & 0.9043 & $0.0476 * *$ & & & \\
\hline $\begin{array}{l}\text { No Issuance of Note } \\
\text { Instruments }\end{array}$ & 2.6119 & 1.1010 & $0.0177 * *$ & & & \\
\hline Rights to Enforce & & & & 1.9569 & 0.8513 & $0.0215 * *$ \\
\hline & $\mathrm{R}^{2}$ & 0.4205 & & $\mathrm{R}^{2}$ & 0.3444 & \\
\hline Classification Accuracy & Missed & Correct & & Missed & Correct & \\
\hline Resubstitution & 2 & 84 & & 5 & 81 & \\
\hline Predict most recent 10 cases & 0 & 10 & & 0 & 10 & \\
\hline
\end{tabular}

** Significant at $0.05 ; * * *$ Significant at 0.01

\section{Judicial Forum}

In Table 5, the fact-oriented decision model, as well as the opinion-oriented model, shows that no judicial forum effect exists. That is, factors considered by the Tax Court and the Federal District Courts do not differ. First, the dummy variable of "Court" is not significant in either model under logistic regression and discriminant analysis. The value of the court dummy variable is " 1 " for Tax Court cases and "2" for District Court cases. Second, the holdout method is employed in the models. The Tax Court observations and the District Courts cases are used as training data and holdout sample, respectively. The results show that the hit ratios in all models are higher than the chance criterion probability. The hit ratios in discriminant analysis exceed the adjusted chance criterion probability (Hair et al. 2005). Third, a counterpart to the Chow test in logistic regression finds that the judicial forum effect is not significant in either the fact-oriented decision model $(\mathrm{p}=0.3512)$ or the opinion-oriented model $(\mathrm{p}=0.7194)$. Finally, both the fact-oriented and the opinion-oriented decision models conclude that the influential factors considered by the Tax Court and the Federal District Courts are not significantly different. 
Panel A: Discriminant Analysis

Table 4: Stability of the "Best" Models

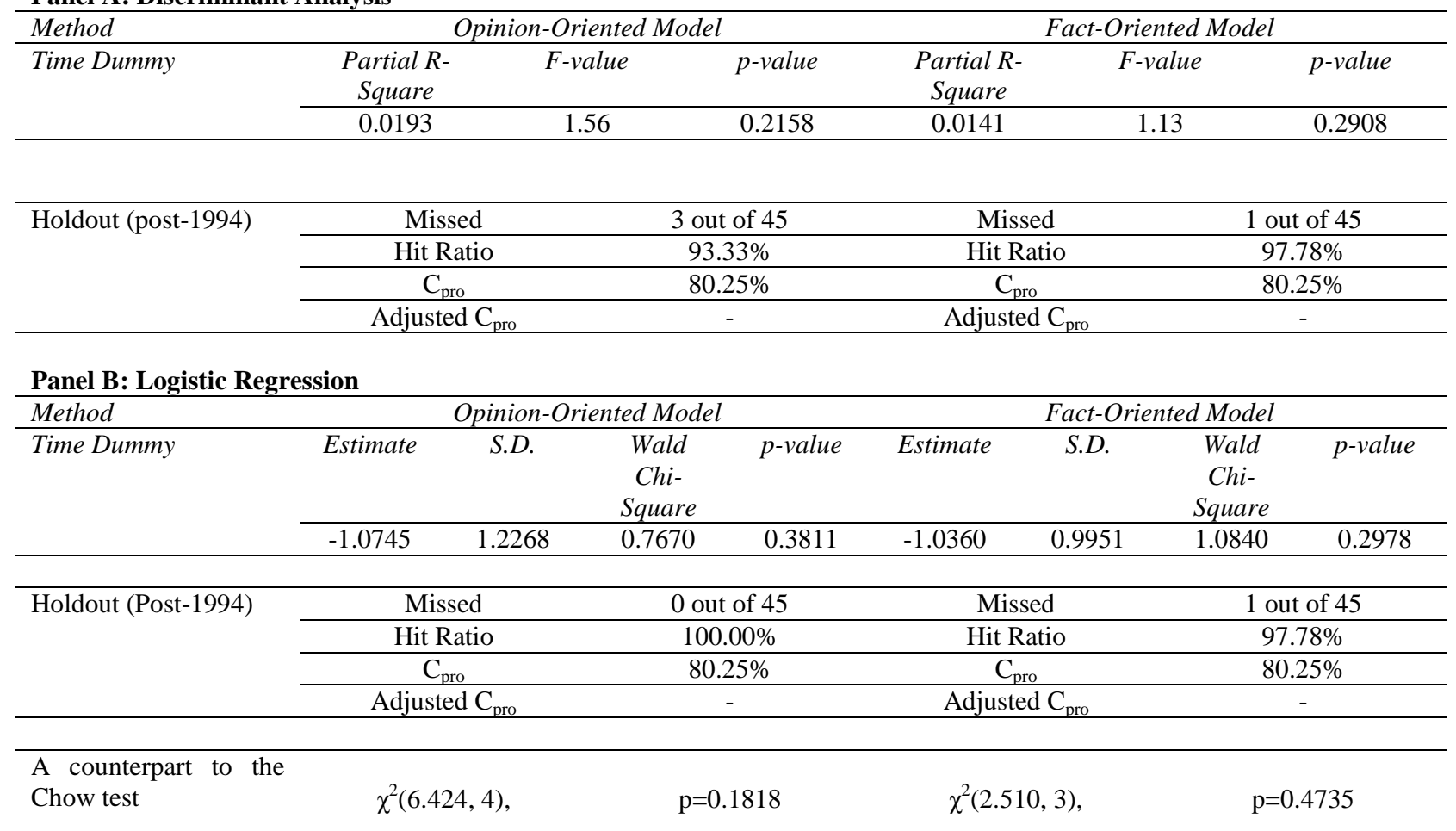

\section{Logistic Regression vs. Discriminant Analysis}

Logistic regression and discriminant analysis often are used in macro-case analysis research. However, choosing between logistic regression and discriminant analysis to provide a better model might be a concern. ${ }^{\mathrm{X}}$ Maddala (1991) indicates that, where the independent variables are not normally distributed, using logistic regression analysis is better than using discriminant analysis. On the other hand, if a normal distribution exists, discriminant analysis is preferred. The Hausman statistic (Lo 1986; Maddala 1991) can be used to test the multivariate normality. The coefficient and covariance matrices for the logit model and the discriminant analysis are obtained from the transformation between the linear probability model and the logit model/discriminant analysis (Maddala 1991, p. 791) ${ }^{\mathrm{xi}}$ Chi-Square tests in both the fact-oriented model and the opinion-oriented model are significant at the 0.01 level $(\mathrm{p}<0.0001)$. That is, the logistic regression model should outperform discriminant analysis. Tables 3 and 4 somewhat confirm this expectation. In Table 3, with the opinion-oriented approach, the logistic regression model misclassifies two observations while the discriminant analysis misses three (the resubstitution method) and five cases (the cross-validation method). Table 4 shows that the logistic regression model correctly predicts all of the observations, but the discriminant analysis misclassifies three cases. However, with the fact-oriented approach, the results are mixed. The logistic regression model in Tables 3 and 4 does not show better classification accuracy than the discriminant model. Nevertheless, the overall results in this study provide some evidence that the logistic regression model performs better than the discriminant analysis. 
Table 5: Judicial Forum Effect in the "Best" Models

\begin{tabular}{|c|c|c|c|c|c|c|}
\hline Method & & -Oriente & & & Oriented & \\
\hline Court Dummy & $\begin{array}{l}\text { Partial R- } \\
\text { Square }\end{array}$ & $F$-value & p-value & $\begin{array}{l}\text { Partial R- } \\
\text { Square }\end{array}$ & $F$-value & $p$-value \\
\hline & 0.0066 & 0.60 & 0.4397 & 0.0002 & 0.01 & 0.9036 \\
\hline
\end{tabular}

\begin{tabular}{|c|c|c|c|c|c|}
\hline \multirow{4}{*}{\multicolumn{2}{|c|}{$\begin{array}{l}\text { Holdout } \\
\text { Courts) }\end{array}$}} & Missed & 1 out of 12 & Missed & 1 out of 12 \\
\hline & & Hit Ratio & $91.67 \%$ & Hit Ratio & $91.67 \%$ \\
\hline & & $\mathrm{C}_{\text {pro }}$ & $62.5 \%$ & $\mathrm{C}_{\mathrm{pro}}$ & $62.5 \%$ \\
\hline & & Adjusted $\mathrm{C}_{\text {pro }}$ & $78.13 \%$ & Adjusted $\mathrm{C}_{\mathrm{pro}}$ & $78.13 \%$ \\
\hline
\end{tabular}

Panel B: Logistic Regression

\begin{tabular}{|c|c|c|c|c|c|c|c|c|}
\hline \multirow{3}{*}{ Method } & \multicolumn{4}{|c|}{ Opinion-Oriented Model } & \multicolumn{4}{|c|}{ Fact-Oriented Model } \\
\hline & Estimate & S.D. & $\begin{array}{c}\text { Wald } \\
\text { Chi- } \\
\text { Square }\end{array}$ & $p$-value & Estimate & S.D. & $\begin{array}{c}\text { Wald } \\
\text { Chi- } \\
\text { Square }\end{array}$ & $p$-value \\
\hline & -0.1638 & 1.0609 & 0.0239 & 0.8773 & 0.3841 & 0.7979 & 0.2318 & 0.6302 \\
\hline \multirow{4}{*}{$\begin{array}{l}\text { Holdout } \\
\text { Courts) }\end{array}$} & \multicolumn{2}{|c|}{ Missed } & \multicolumn{2}{|c|}{3 out of 12} & \multicolumn{2}{|c|}{ Missed } & \multicolumn{2}{|c|}{3 out of 12} \\
\hline & \multicolumn{2}{|c|}{ Hit Ratio } & \multicolumn{2}{|c|}{$75 \%$} & \multicolumn{2}{|c|}{ Hit Ratio } & \multicolumn{2}{|c|}{$75 \%$} \\
\hline & \multicolumn{2}{|c|}{$\mathrm{C}_{\mathrm{pro}}$} & \multicolumn{2}{|c|}{$62.5 \%$} & \multicolumn{2}{|c|}{$\mathrm{C}_{\text {pro }}$} & \multicolumn{2}{|c|}{$62.5 \%$} \\
\hline & \multicolumn{2}{|c|}{ Adjusted $\mathrm{C}_{\text {pro }}$} & \multicolumn{2}{|c|}{$78.13 \%$} & \multicolumn{2}{|c|}{ Adjusted $\mathrm{C}_{\text {pro }}$} & \multicolumn{2}{|c|}{$78.13 \%$} \\
\hline $\begin{array}{l}\text { A counterpart to the } \\
\text { Chow test }\end{array}$ & \multicolumn{2}{|c|}{$\chi^{2}(1.341,3)$} & \multicolumn{2}{|c|}{$\mathrm{p}=0.7194$} & \multicolumn{2}{|c|}{$\chi^{2}(2.093,2)$} & \multicolumn{2}{|c|}{$\mathrm{p}=0.3512$} \\
\hline
\end{tabular}

\section{DISCUSSION AND CONCLUSION}

This study addresses the coding issue in a traditional opinion-oriented model in macro-case analysis research and also suggests a supplemental fact-oriented approach to improve model predictability. Both the factoriented and the opinion-oriented approaches are applied to recent Tax Court cases decided during years 1982-2008, which correspond to the section 385 debt-equity dilemma. The results show that the influential factors differ under the fact-oriented and the opinion-oriented decision models. Also, most model stability tests in the decision models indicate that the "best" models are quite stable during the sample period. Furthermore, both the fact-oriented and the opinion-oriented approaches suggest that the judicial forum effect between the Tax Court and the Federal District Courts does not exist. Meanwhile, the results find that the logistic regression model is preferred to the discriminant model in terms of classification accuracy.

The only factor included in all of the "best" decision models found in this study is "Source of Payment." Two reasons may explain this finding. First, "Source of Payment" is a subjective factor rather than an objective one. Bond (1977, p. 132) states, "The variable, is repayment dependent on uncertain profits, involves a subjective judgment of how the judge is going to reason with this factor." Second, the content of "Source of Payment" is closely related to business risk, which could be viewed as a dependent variable rather than an independent variable (Plumb 1971, p. 411). Unfortunately, even the fact-oriented decision model cannot eliminate the subjectivity of this variable. That is, the coding scheme of this factor in the fact-oriented model is also relying on a subjective term, "reasonable expectation." The perception of a judge and a taxpayer regarding what is "reasonable expectation" may not always match perfectly.

Nevertheless, other independent variables included in fact-oriented decision models, such as "Capitalization," "Payment of Interest," "Rights to Enforce," and "Management," have very objective definitions. The objectivity of these influential factors can improve the manageability of model predictability, which makes the prediction of a judicial decision more feasible. On the other hand, independent variables identified in opinion- 
oriented decision models such as "Capitalization" and "No Issuance of Note Instruments" provide no feasible, operational meanings. For example, as suggested by the opinion-oriented decision models, a litigating taxpayer can acknowledge that "Capitalization" is an influential factor. Nevertheless, he or she cannot know whether the court will evaluate his or her firm as one capitalized on a thin or thick basis. Accordingly, the taxpayer cannot predict the judicial outcome. Likewise, if a note was not issued in the case, a petitioner would not know how the court will assess the factor "No Issuance of Note Instruments." Particularly, the judge may follow either Cashman [TCM 1991-359] favoring equity or Flint [TCM 2001-276] weighing neutral. Again, the petitioner is unable to predict the judicial outcome.

This study has several limitations. First, although the study attempts to provide a fact-oriented approach based on "objective" facts rather than on "subjective" opinions, the fact-oriented decision model does not entirely eliminate the subjectivity of influential factors. The tainted objectivity may lead a fact-oriented decision model to the main flaw of the opinion-oriented decision model - "lack of predictivity" for cases beyond the sample (Hariton 1994, p. 505). Second, due to the ambiguity of the language found in the cases, two independent coders can reduce, but not fully eliminate, random coding errors (Pollard \& Copeland 1985). Lastly, the definition of an independent variable in a fact-oriented decision model is ascertained by the model builder. Different definitions could affect the coding and the results of a fact-oriented decision model as well.

Although a fact-oriented approach has drawbacks, most of its limitations are inherent difficulties within the macro-case research approach. Both the fact-oriented and the opinion-oriented decision models could have the same concerns. Nevertheless, while an opinion-oriented approach can reveal the influential factors considered by judges in the precedents, a fact-oriented approach provides a decision model with predictability which does not exist in an opinion-oriented approach. Therefore, a fact-oriented approach can be used by management or practitioners as a supplemental method to the opinion-oriented approach.

Future research could address these issues in several ways. First, decompositions of the subjective factors into objective variables in a fact-oriented approach could be pursued. Second, changing the definitions of independent variables in a fact-oriented decision model might improve the classification accuracy of the model. Finally, a fact-oriented approach could be applied to other tax modeling topics such as dealer-versus-investor, employee-versus-independent contractor, and salary-versus-constructive dividends.

\section{AUTHOR INFORMATION}

Wei-Chih Chiang is an assistant professor of accounting at the University of Houston - Victoria. Dr. Chiang received his doctoral degree from Louisiana Tech University. His research interests are in tax and financial accounting. E-mail: chiangw1@uhv.edu

Ted D. Englebrecht received his BSBA and MBA from East Carolina University and his MAcc. and Ph. D. from the University of South Carolina. He holds the Smolinski Eminent Scholar Chair in Accountancy at Louisiana Tech University. Also, Professor Englebrecht is the 1992 Outstanding Discussion Leader for the Georgia Society of CPAs and the recipient of the 1991 and 1997 Outstanding Discussion Leader Award of the Florida Institute of CPAs. In 2004, Dr. Englebrecht received the Society of Louisiana CPAs Lifetime Achievement Award. He has published over 175 articles in the Accounting Review, Journal of American Taxation Association, Accounting Horizons, Journal of Accounting \& Public Policy, Advances in Accounting, Advances in Taxation, the Southern Economic Journal, and other professional and academic journals. E-mail: TEnglebr@cab.latech.edu

\section{REFERENCES}

1. Barniv, R., Danvers, K., and Healy-Burress, J. P. (2005), An empirical examination of state and local revocations of tax-exempt status for nonprofit hospitals, The Journal of the American Taxation Association, Vol. 27, (2), pp. 1-25.

2. Bond, J. (1977), An empirical investigation of court-determined debt-equity attributes for federal income tax purposes, Doctoral dissertation, University of South Carolina. 
3. Burns, J. and Groomer, S. (1983), An analysis of tax court decisions that assess the profit motive of farming-oriented operations, The Journal of the American Taxation Association, Vol. 5, Fall, pp. 23-39.

4. Copeland, R.,. Taylor, R, and Brown, S. (1981), Observation error and bias in accounting research, Journal of Accounting Research, Vol. 19, (1), pp. 197-207.

5. Englebrecht, T. and Bundy, T. (2004), An empirical examination of investor or dealer status in real estate sales, Advances in Taxation, Vol. 16, pp. 55-72.

6. Englebrecht, T., Chiang, W. C., and Wang, Y. (2008), An empirical assist for management in resolving the debt versus equity dilemma, Journal of Business and Accounting, Vol. 1, (1), pp. 121-137.

7. $\quad$ Greene, W. (2003), Econometric Analysis, Upper Saddle River, NJ: Prentice Hall.

8. Hair, J., Anderson, R., Tatham, R., and Black, W. (2005), Multivariate Data Analysis, Upper Saddle River, NJ: Prentice Hall.

9. Hariton, D. (1994), Distinguishing between equity and debt in the new financial environment, Tax Law Review, Vol. 49, (Spring), pp. 499-524.

10. Horvitz, J. and Finley, D. (1979), A macro-case analysis approach to tax research - A comment, The Accounting Review, Vol. 54, (3), pp. 637-640.

11. Johnson, D. (1998), Applied Multivariate Methods for Data Analysts, Pacific Grove, CA: Brooks/Cole Publishing Company.

12. Kramer, S. (1982), Blockage: valuation of large blocks of publicly traded stocks for tax purposes. The Accounting Review, Vol. 57, (January), pp. 70-87.

13. Kutner, M., Nachtsheim, C., Neter, J., and Li, W. (2005), Applied Linear Statistical Models, New York, NY: McGraw-Hill Irwin.

14. Lo, A. (1986), Logit vs. discriminant analysis: A specification test and application to corporate bankruptcies, Journal of Econometrics, Vol. 31, (March), pp. 151-178.

15. Maddala, G. (1991), A perspective on the use of limited-dependent and qualitative variables models in accounting research, The Accounting Review, Vol. 66, (4), pp. 788-807.

16. Misiewicz, K. (1977), A macro-case analysis approach to tax research, The Accounting Review, Vol. 52, (4), pp. 935-938.

17. Misiewicz, K. (1979), A macro-case analysis approach to tax research - A reply, The Accounting Review , Vol. 54, (3), pp. 641-642.

18. Plumb, W. (1971), The federal income tax significance of corporate debt: A critical analysis and a proposal, Tax Law Review, Vol. 26, (March), pp. 369-640.

19. Pollard, W. and Copeland, R. (1985), Evaluating the robustness of multivariate tax models to errors: A section 162(a)(2) illustration, The Journal of the American Taxation Association, Vol. 7, (Fall), pp. 7-18.

20. Pollard, W. and Copeland, R. (1987), Empirical modeling of section 162(a)(2) tax court decisions: Identifying the location of a tax home, Journal of Business Research, Vol. 15, pp. 55-69.

21. Porcano, T. (1982), An empirical analysis of the tax court's determination of reasonable compensation, Decision Science, Vol. 13, pp. 285-302.

22. Robison, J. (1983), Tax court classification of activities not engaged in for profit: Some empirical evidence, The Journal of the American Taxation Association, Vol. 5, (Fall), pp. 7-22.

23. Robertson, P., Daughtrey, Z., and Burckel, D. (1990), Debt or equity? An empirical analysis of tax court classification during the period 1955-1987, Tax Notes, Vol. 47, (May 7, 1990), pp. 707-717.

24. Webb, T., Englebrecht, T., Bisping, T., and Hanke, S. (2008), An empirical assist in resolving the classification dilemma of workers as either employees or independent contractors, Journal of Applied Business Research, Vol. 24, (2), pp. 45-65.

25. Whittington, R. and Whittenburg, G. (1980), Judicial classification of debt versus equity - An empirical study, The Accounting Review, Vol. 55, (3), pp. 409-418. 


\title{
APPENDIX: VARIABLE DESCRIPTIONS AND CODING SCHEMES IN MODELS
}

\author{
I. The Opinion-Oriented Decision Model
}

Variable

Number

Variable/Description

Code

Dependent Variable

Y Decision: court's determination for the issue

The court determines the transfer to be a debt

The court determines the transfer to be an equity

1

\section{Independent Variables}

X1 Name: the name given to the certificate used by the parties

The court weighs this factor in favor for debt

The court does not state this factor, weighs little in this factor,

or states this factor as neutral.

The court weighs this factor in favor for equity

Maturity Date: whether a maturity date exists

The court weighs this factor in favor for debt

The court does not state this factor, weighs little in this factor, or states this factor as neutral.

The court weighs this factor in favor for equity

X3 Source of Payment: whether the repayment depends on the earnings

The court weighs this factor in favor for debt

The court does not state this factor, weighs little in this factor,

or states this factor as neutral.

The court weighs this factor in favor for equity

X4 Rights to Enforce: whether there is a definite obligation to repay the advance

The court weighs this factor in favor for debt

The court does not state this factor, weighs little in this factor,

or states this factor as neutral.

The court weighs this factor in favor for equity

X5 Management: whether the transferor increases participation or control after the transaction

The court weighs this factor in favor for debt

The court does not state this factor, weighs little in this factor,

or states this factor as neutral.

The court weighs this factor in favor for equity

X6 Subordination: whether the advance has an inferior status to that of regular corporate creditors

The court weighs this factor in favor for debt

The court does not state this factor, weighs little in this factor,

or states this factor as neutral.

The court weighs this factor in favor for equity

X7 Capitalization: whether thin or thick capitalization exists

The court weighs this factor in favor for debt

The court does not state this factor, weighs little in this factor,

or states this factor as neutral.

The court weighs this factor in favor for equity 
X8 Identity of Interest: whether advances are made by stockholders in proportion to their respective stock ownership

The court weighs this factor in favor for debt

The court does not state this factor, weighs little in this factor,

or states this factor as neutral.

The court weighs this factor in favor for equity

X9 Payment of Interest: whether interest provision exists and interest is actually paid

The court weighs this factor in favor for debt

The court does not state this factor, weighs little in this factor,

or states this factor as neutral.

The court weighs this factor in favor for equity

0

$-1$

1

0

$-1$

X10 Outsider Loan: whether the transferee is able to borrow funds from outside sources

The court weighs this factor in favor for debt

The court does not state this factor, weighs little in this factor,

or states this factor as neutral.

The court weighs this factor in favor for equity

1

0

$-1$
Use of Advance: whether the advance is used to acquire capital assets

The court weighs this factor in favor for debt

The court does not state this factor, weighs little in this factor,

or states this factor as neutral.

The court weighs this factor in favor for equity

1

0

$-1$

1

0

$-1$

The court weighs this factor in favor for equity

X13 Collateral: whether the transfer is secured by assets

The court weighs this factor in favor for debt

The court does not state this factor, weighs little in this factor, or states this factor as neutral.

The court weighs this factor in favor for equity

0

$-1$

1

The court weighs this factor in favor for equity

The court weighs this factor in favor for debt

The court does not state this factor, weighs little in this factor,

X15 Rights Enforced: whether rights are enforced as default

The court weighs this factor in favor for debt

The court does not state this factor, weighs little in this factor, or states this factor as neutral.

The court weighs this factor in favor for equity

The court weighs this factor in favor for equity

X17 No Issuance of Note Instruments: where note instruments are not issued

The court weighs this factor in favor for debt

The court does not state this factor, weighs little in this factor,

or states this factor as neutral

The court weighs this factor in favor for equity

(1)

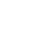

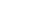

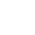

(1)

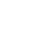


X18 Instrument Issued: whether loan/equity instruments are issued Instrument issued and the court weighs this factor in favor for debt Instrument issued and the court does not state this factor, weighs little in this factor, or states this factor as neutral; Related information is not stated or unclear

Instrument issued and the court weights in favor for equity

\section{The Fact-Oriented Decision Model}

Variable

Number

Variable/Description

Code

\section{Dependent Variable}

Y Decision: court's determination for the issue

The court determines the transfer to be a debt

The court determines the transfer to be an equity

\section{Independent Variables}

X1 Name: the name given to the certificate used by the parties

Loan instruments are issued for the transfer

Related information is not stated or unclear, or neither loan instruments nor stocks are issued for the transfer.

Equity Instruments are issued for the transfer

X2 Maturity Date: whether a maturity date exists

A fixed maturity date is present on loan instruments

Related information is not stated or unclear

No fixed maturity date is present on loan instruments

X3 Source of Payment: whether the repayment depends on the earnings

Reasonable expectation of repayment at the time of the transfer, or

has sources other than earnings to repay

Related information is not stated or unclear

Repayment is possible only out of corporate earnings, or the

repayment is remote

X4 Rights to Enforce: whether there is a definite obligation to repay the advance

A definite, unconditional obligation to repay the advance

Related information is not stated or unclear, even if notes are signed for

the transfer

No definite, unconditional obligation to repay the advance

X5 Management: whether the transferor increases participation or control after the transaction Not granted any increased voting power or participation in management by virtue of the advance

Related information is not stated or unclear; Sole ownership

Granted any increased voting power or participation in management

by virtue of the advance

X6 Subordination: whether the advance has an inferior status to that of regular corporate creditors

The advance has a status equal or superior to that of other creditors

Related information is not stated or unclear, or no other creditors exist

The advance has a status inferior to that of other creditors 
X7 Capitalization: whether thin or thick capitalization exists

When transferring, the debt to equity ratio is under the "safe harbor" of

Rec. Sec. 1.385-6(f)(3) (i.e., external debt to equity ratio 10:1 or internal debt

to equity ratio $3: 1$ ), or the court states that it is not a thin capitalization

when the debt to equity ratio is not available

1

Related information is not stated or unclear

When transferring, the debt to equity ratio is not within the "safe harbor"

of Reg. Sec. 1.385-6(f)(3) (i.e., external debt to equity ratio 10:1 or internal

debt to equity ratio $3: 1$ ), or the court states that it is a thin capitalization

when the debt to equity ratio is not available

$-1$

X8 Identity of Interest: whether advances are made by stockholders in proportion to their respective stock ownership Advances made by stockholders are not (approximately) in proportion to their respective stock ownership

1

Related information is not stated or unclear; Sole ownership

Advances are made by stockholders (approximately) in proportion to

their respective stock ownership

X9 Payment of Interest: whether interest provision exists and interest is actually paid Specific provision of interest payment and interest is paid

Related information is not stated or unclear, or specific provision of

interest payment is stated but information of interest payment is not

stated or unclear

No provision for the payment of interest, or no any interest is paid

X10 Outsider Loan: whether the transferee is able to borrow funds from outside sources

The petitioner is able to obtain outsider loans under

the same/different terms at the time the transfer is made

Related information is not stated or unclear

The petitioner is unable to obtain outsider loans under

the same/different terms at the time the transfer is made

0

$-1$

1

0

$-1$

1

0

$-1$

X11 Use of Advance: whether the advance is used to acquire capital assets

Mainly used for working capital

Related information is not stated or unclear

Mainly used for purchasing capital assets or initial working capital

0

$-1$

X12 Failure of Repaying Advance: whether the advance is repaid

The advance is repaid on the due date

Related information is not stated or unclear, or there is no due date

Failure of repaying the advance in full on the due date, or the repayment

is postponed

X13 Collateral: whether the transfer is secured by assets

The transfer is secured

Related information is not stated or unclear

The transfer is not secured

1

$-1$

X14 Sinking Fund: whether a sinking fund exists

Sinking fund for repayment exists

Related information is not stated or unclear

Sinking fund for repayment does not exist

1

0

$-1$

Rights Enforced: whether rights are enforced as default

Yes

Related information is not stated or unclear

No 
X16 Formal Documentation: whether documents or records indicate loans

Formal documentation indicates a loan

Related information is not stated or unclear, or lack of records

Formal documentation indicate an equity

1

0

$-1$

X17 No Issuance of Note Instruments: whether note instruments are issued Loan instruments are issued for the transfer

Related information is not stated or unclear

Loan instruments are not issued for the transfer

X18 Instrument Issued: whether loan/equity instruments are issued

Loan instruments are issued for the transfer

Related information is not stated or unclear, or no instruments are issued

for the transfer

Equity instrument are issued for the transfer

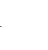

1

\section{ENDNOTES}

\footnotetext{
i See the following examples. In Recklitis [91 TC 874], the Tax Court viewed the factor of "Participation in Management" in favor of debt where participation did not increase, but the Tax Court in American Offshore, Inc. [97 TC 579] evaluated the factor neutral under the same circumstance. Regarding the factor of "Failure of Repayment," the Tax Court in Seller [TC Memo 2000-235] weighed it against debt where there was no fixed maturity date and no repayment was made, but the Tax Court in Flint Industries weighed it neutral under the same situation.

ii This approach is different from Bond (1977) and Robison (1983), which allow facts mentioned in the section of findings of fact but not discussed in the opinion section to be coded as factors in their decision models.

iii Bond (1977, p. 132) realizes this issue and states, "The factors considered in determining the values for the discriminant analysis were not always set out in the opinion. In a significant number of cases, the value of the variable was determined from the facts. In these cases, the judge may not have considered the factor in reaching his decision."

iv The traditional debt-equity principles usually are applied to guaranteed debt in cases where the IRS argues the advances made in the form of a guaranteed debt are capital contributions in substance. See, for example, Plantation Patterns, Inc. [462 F. 2d $712\left(5^{\text {th }}\right.$ Cir. 1972) ]. However, the Tax Court declined to apply the debt-equity analysis used in Plantation Patterns, Inc. to the guarantee of a loan in Estate of Leavitt [90 TC 206, at 216].

${ }^{v}$ The cases of Sigmon [TCM 1988-377] and PK Ventures [TCM 2006-36] include two useful observations. Therefore, the sample includes 84 cases but 86 observations from the Tax Court.

${ }^{v i}$ See, for example, Dunnegan [TCM 2002-119].

vii In CMA Consolidated, Inc. [TCM 2005-16], the Tax Court considers both "Name" and "Instrument Issued." However, only "Instrument Issued" is evaluated in Boyko [TCM 1998-67].

viii Englebrecht and Bundy (2004) handle missing variables conservatively. That is, missing data in a case are coded against taxpayers. Nevertheless, this approach overstates the importance of the missing data in revealing the court's decision process, and, hence, is not adopted in the current study.

ix In Price [TCM 1997-61], for instance, the fact related to "Capitalization" is not revealed, but the court states the company was "inadequately capitalized." In this case, the independent variable "Capitalization" is coded in favor of equity in both decision models.

${ }^{x}$ Englebrecht and Bundy (2004) provide results generated by the LOGIT, PROBIT, and discriminant analysis models. However, neither the issue of comparing the variables included in the final models nor the differences of findings among the three models are addressed. However, Pollard and Copeland (1987) find PROBIT models achieve equal or inferior classification accuracy than do linear discriminant models.

${ }^{x i}$ Only seven independent variables considered of importance in the "best" models are used for calculation of the Hausman statistic.
} 
NOTES 